\title{
The Environmental Kuznets Curve: Seeking Empirical Regularity and Theoretical Structure
}

\author{
Richard T. Carson*
}

\section{Introduction}

Long before the environmental Kuznets curve (EKC), which shows pollution at first increasing and then decreasing as income increases (see Figure 1), became enshrined in standard economic principles texts (e.g., Frank and Bernanke 2005), a very different view was set out by Ehrlich and Holden (1971). Much of the science and policy community still subscribes to their famous IPAT equation ( $\mathrm{I}=\mathrm{PAT}$ ), which relates Impact (e.g., pollution or natural resource use) to Population, Affluence (often proxied with per capita income), and Technology. ${ }^{1}$ The IPAT view generated considerable controversy and lay behind Ehrlich's best-selling popular book The Population Bomb (1968) and the Club of Rome's Limits to Growth (Meadows et al. 1972). These books saw population growth coupled with growing affluence as the primary forces driving adverse environmental impacts. They viewed technology as a neutral or even mildly beneficial factor, although some environmentalists such as Commoner (1972) saw it as the main destructive force.

Economists engaged this debate with three counterarguments (e.g., Kneese and Ridker 1972; Nordhaus 1973; Solow 1973). The first was that technological progress is a large positive influence that is resource conserving, pollution reducing, and growing at a rate large enough to offset the impacts of population growth and rising affluence. This view was diametrically opposed to the Club of Rome approach in which adverse environmental impact estimates were driven by exponential growth in the use of resources but not technological progress. The second pointed out that the IPAT equation effectively lacked any behavioral response to the increasingly adverse impact being modeled. In the Club of Rome's world, people choked to death on pollution, froze, or starved in enormous numbers without the explicit and implicit

\footnotetext{
*Department of Economics, University of California, San Diego; e-mail: rcarson@ucsd.edu

Max Auffhammer, Suzanne Leonard and Lois Winsen provided a number of useful comments. Any remaining errors are those of the author. Johanna Bible provided helpful research assistance.

${ }^{1}$ In a slightly different form, IPAT is known as the Kaya Identity, which plays a central role in the Intergovernmental Panel on Climate Change (IPCC) estimates of future $\mathrm{CO}_{2}$ emissions. In these estimates, total $\mathrm{CO}_{2}$ emissions are a product of population, per capita GDP, energy use per capita, and $\mathrm{CO}_{2}$ emissions per unit of energy consumed.
}

Review of Environmental Economics and Policy, volume 4, issue 1, winter 2010, pp. 3-23

doi:10.1093/reep/rep021

Advance Access publication on December 22, 2009

(C) The Author 2009. Published by Oxford University Press on behalf of the Association of Environmental and Resource Economists. All rights reserved. For permissions, please email: journals.permissions@oxfordjournals.org 


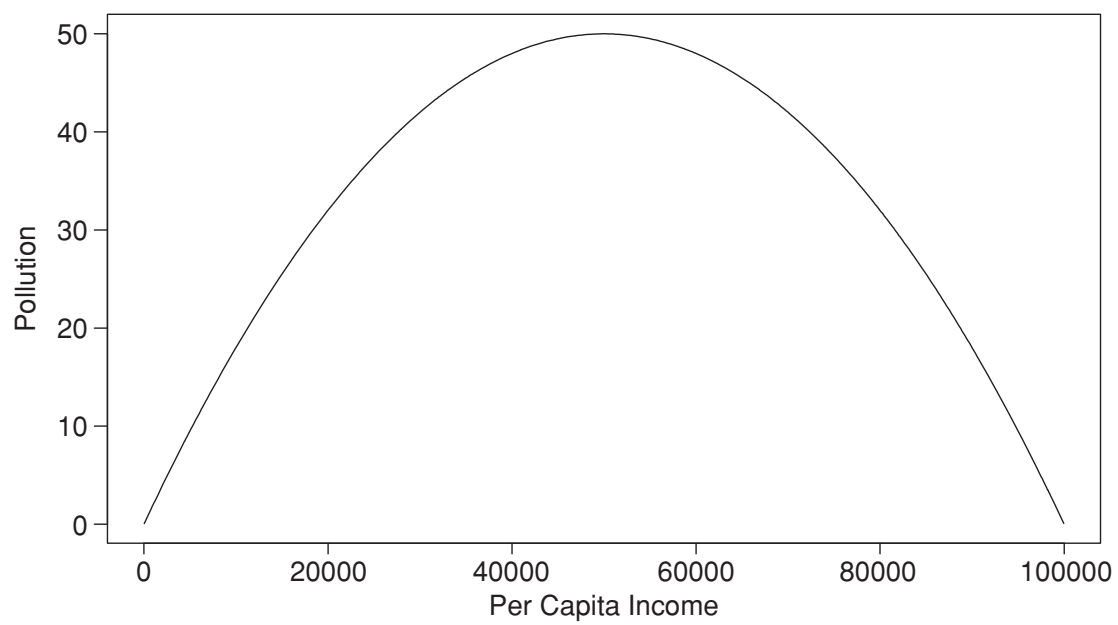

Figure I Stylized environmental Kuznets curve.

prices of the economic system changing in any way. ${ }^{2}$ The third noted substantial problems with both the quantity and quality of the data underlying the IPAT/Club of Rome view.

There is some irony that the initial and highly influential studies of the EKC (Grossman and Krueger 1991; Shafik and Bandyopadhyay 1992) never referenced the IPAT/Club of Rome debate. Perhaps this is not surprising as the concept of an EKC was originally advanced by trade/development economists in the context of an international trade agreement rather than environmental/resource economists in a pollution control context. ${ }^{3}$ But the question at the heart of the EKC debate was almost identical to the one at the heart of the IPAT/Club of Rome debate: does economic growth need to be slowed, if not stopped, in order to avoid increasing harm to the environment? Grossman and Krueger $(1991,1995)$ provided an answer that seemed to contradict the arguments against joining the North American Free Trade Agreement (NAFTA), which were based on increasing environmental degradation, particularly in Mexico (Daly 1993). Shafik and Bandyopadhyay's (1992) work provided a justification for the World Bank's (1992) position that increasing income would likely help improve a wide array of environmental indicators. Ultimately both studies fall victim to the same criticisms brought against the IPAT/Limits to Growth framework: that the underlying model is misspecified, a behavioral response mechanism is missing, and poor-quality data underlie the estimates.

The lasting contribution of the EKC literature has been to shift the conventional wisdom of rank-and-file economists and many policymakers toward a belief that economic growth is

\footnotetext{
${ }^{2}$ The passage of groundbreaking environmental laws across the developed world (starting in the late 1960s) is the best indication that the bleak world foreseen by the Club of Rome would not be allowed to manifest itself in the wealthiest countries.

${ }^{3}$ However, the link between IPAT and the EKC was quickly noted by environmental economists such as Stern, Common, and Barbier (1996), who pointed out: "If the EKC hypothesis held generally, it could imply that instead of being a threat to the environment as argued in, for example, The Limits to Growth (Meadows et al. 1972), economic growth is the means to environmental improvement."
} 
good for the environment. In this regard, Beckerman (1992) represents an early influential statement in World Development. Official U.S. recognition of the EKC in its standard sense of an income-driven U-shaped pollution function across political jurisdictions came in the 1999 Economic Report of the President (U.S. Council of Economic Advisors, 1999). ${ }^{4}$ The title of an opinion piece in the Sydney Morning Herald, "Growth Is the Key to Protecting the Environment, Not Its Enemy” (M. Robinson, 9 September 2008, p. 10), sums up the popular view of growth advocates. However, many, perhaps even most, of those currently working in this area have come to believe that this popular view is wrong (e.g., Arrow et al. 1995; Stern 2004).

But the push back against the EKC has not been toward the IPAT model, but rather toward a belief that both views are fatally flawed. This should not be surprising. It is easy to show that the IPAT model is simply a restricted version of the EKC. The casual empiricism characterizing much of the early EKC literature established the stylized fact that environmental quality tends to be positively, not negatively, correlated with income in wealthier countries. This suggests that the EKC specification is a distinct improvement over the IPAT model. However, the problem with the EKC lies with the assumption of a causal role of income growth and the inadequacy of reduced-form specifications that presume that a common income-related process, conditional on fixed effects for political jurisdictions and a few observable covariates, adequately describes the generation of the pollutant of interest.

The intent of this article is not to comprehensively review the sprawling EKC literature, as several reviews are available. ${ }^{5}$ Rather it is to look at how the current state of play concerning the EKC came about and to discuss what can and should be salvaged.

The organization of the article is as follows. First I summarize the initial reactions and questions raised about the EKC. I then look at the theoretical literature on the EKC. This is followed by an examination of empirical issues and findings, turning first to Mexico (the focus of Grossman and Krueger's [1991] initial work) and what actually happened following the implementation of NAFTA, and then the United States, Malaysia, and China, which provide key insights to unraveling the EKC puzzle. Next I discuss econometric issues that have been raised concerning the EKC, particularly with respect to data quality and inferring a causal relationship. These issues provide much of the impetus for a revisionist view that little substance lies behind the EKC and a more nuanced view of a relationship in which income works through other factors. I conclude by discussing what can be learned from our twenty-year fascination with the EKC.

\footnotetext{
${ }^{4}$ This formulation is also a staple in environmental economics textbooks. See Russell (2001) for a clear statement of the standard version of the EKC model and its interpretation "as [empirical] evidence for the notion that, eventually, income growth will, one way or another, tend to 'fix' environmental problems," and an easily digestible discussion of the conceptual and empirical problems with this view.

${ }^{5} \mathrm{~A}$ broad-ranging general review is Dinda (2004). Focusing on the empirical literature, Dasgupta et al. (2002) and Yandle, Bhattarai, and Vijayaraghavan (2004) put forth an optimistic picture, while de Bruyn, van den Bergh, and Opschoor (1998) and Stern (2004) put forth bleak pictures. Cavlovic et al. (2000) provide a meta-analysis of the early empirical results. Copeland and Taylor (2003) and Brock and Taylor (2005) provide extensive discussions of the theoretical models. Closest in spirit to this article is a review by Levinson (2002) that deserves much more attention than it has received.
} 


\section{Initial Reactions and Questions about the EKC}

The initial reaction to Grossman and Krueger (1991) was a flurry of work both empirical and theoretical. Empirical confirmation of their provocative findings soon came from World Bank researchers (Shafik and Bandyopadhyay [1992] and Shafik [1994]). Using additional environmental indicators and more countries, these researchers found either an EKC relationship or monotonically improving environmental quality with income (with the exception of dissolved oxygen in rivers and $\mathrm{CO}_{2}$ ). They also started to use other variables, such as trade indicators and political freedom, as predictors of environmental quality. Panayotou (1993) used a larger set of purely cross-sectional data and found support for a number of EKC relationships. Selden and Song (1994), using the same GEMS (global environmental monitoring system) database as Grossman and Krueger, improved upon the econometric techniques and still found empirical support for an EKC. ${ }^{6}$ Later, Grossman and Krueger (1995) expanded their initial analysis to include additional pollutants available from the GEMS database.

Another important study, by Holtz-Eakin and Selden (1995), found that $\mathrm{CO}_{2}$ emissions were increasing over any plausible income range for the broad set of countries they examined. This result seemed to nicely limit the range of the EKC prediction by making the obvious distinction between local and global externalities and, of course, pointed to the need for global action (e.g., the Kyoto Protocol). ${ }^{7}$

In the popular press, economic growth per se began to be touted as the answer to environmental problems (e.g., Bartlett 1994). ${ }^{8}$ However, this was not quite what Grossman and Krueger (1991) had said. They were clear about the nature of their assumptions and put in the usual caveats typical of careful researchers. They were particularly forthcoming about the fact that the reduced-form nature of their model limited the policy implications of their results. Still Grossman and Krueger (1996) felt compelled to reiterate these points again in a policy forum piece in Environment and Development Economics and to emphasize that "there is nothing inevitable about the relationship between growth and environment that has been observed in the past." Taking on their most prominent critics, Grossman and Krueger noted:

Arrow et al. (1995) conclude, 'economic liberalization and other policies that promote GNP growth are not substitutes for environmental policy'. We would agree. But we would go further and state that neither is the suppression of economic growth or of economic policies conducive to it a suitable substitute for environmental policy.

Interestingly, this statement is consistent with either the repudiation of the IPAT view that growth in income is detrimental to environmental quality or the position that there is no relationship between income growth and environmental quality.

\footnotetext{
${ }^{6}$ Selden and Song (1994) argued the immediacy of urban health problems would drive clean-up efforts.

${ }^{7}$ The Montreal Protocol represents a successful example of developed countries helping to subsidize the phase-out of a global externality, the CFCs, in the developing countries through the diffusion of clean technology.

${ }^{8}$ The difficulty with this line of argument, as Stern, Common, and Barbier (1996) forcefully point out, is that, even if one believed the estimated turning points in the EKC literature, income levels in countries where much of the population lives were substantially below those turning points so that environmental conditions were going to get worse in most places for a long time before they improved.
} 


\section{The Theoretical Literature on the EKC}

The major theoretical advance concerning the possibility of an EKC relationship was made quite early when Grossman and Krueger (1991) pointed out three possible impacts of an increase in economic activity due to a trade agreement. The first was an increase in the scale of current production, the second a change in the composition of current production, and the third a shift in production techniques. The first factor naturally leads to more pollution in the face of economic growth that results from freer trade. The second has ambiguous effects in any particular country but could not result in a reduction in pollution everywhere. This leads to the possibility of pollution havens and a "race to the bottom" that lay behind the debate on NAFTA. Only the third factor points to the possibility of lower pollution levels being associated with economic growth.

Grossman and Krueger were not the first to address the influence of trade on pollution. Moreover, the more general overarching theoretical result (e.g., Pethig 1976) that differences in pollution control costs across countries could give the country with lax standards a comparative advantage in producing "dirty" goods was well known. In the late 1980s, a related literature emerged (e.g., Sutton 1988) that focused largely on agriculture, the environment, and trade using a computable general equilibrium (CGE) framework. The difficulty with these CGE models was their embodiment of a constant-returns-to-scale assumption to make them tractable that effectively guaranteed the prediction of an adverse environmental outcome. With environmental concerns a flash point for opposing free-trade agreements and empirical evidence suggesting that trade was good for the environment, it is not surprising that theoretical work began filling the void.

López's (1994) paper was one of the first of such papers out of the gate and into print. He looks at stock externalities (e.g., soil erosion) and shows that a key issue is whether producers internalize the externality. If they do, then growth in income/trade will be reflected in improved environmental quality. López notes that this internalization could happen via voluntary cooperative agreements, but for the usual reasons might require corrective government action. He shows that as the substitution elasticity between conventional output and pollution falls and the relative curvature of income in the utility function (the relativerisk-aversion coefficient) falls, an inverse U-shaped income-pollution relationship emerges. The López article was highly influential. Aimed squarely at environmental economists, it invoked both the production and utility sides of the picture as an explanation for the emergence of an empirical EKC under plausible parameter values without removing any of the need for the usual tools to deal with pollution. ${ }^{9}$

The theoretical literature also took a more abstract direction tied to macroeconomic work on optimal growth. Using an overlapping generations approach, John and Pecchenino (1994) "provide a theoretical explanation of the observed correlation between environmental quality and income." They note the possibility of multiple equilibria and overprovision of

\footnotetext{
${ }^{9}$ Selden and Song (1995) soon followed, advancing the idea that pollution abatement expenditures followed a J-curve, increasing rapidly at some point as a country became richer, and that this produced the inverted $\mathrm{U}$ in pollution. They showed that this concept was implicit in some earlier models of optimal growth that incorporated environmental considerations.
} 
environmental quality as well as the potential importance of increasing returns to scale, which gained greater emphasis later. Presciently, they conclude: "The relationship between growth and the quality of the environment is complex."

Jones and Manuelli (1995) and Stokey (1998) provide more satisfying variants from the macro-growth perspective. Jones and Manuelli focus on the interaction between growth, the environment, and collective decision-making. In their model, the young can choose to tax pollution that will exist when they are older. The nature of collective decision-making influences the income-pollution path chosen, and, hence, societal utility. Thus Jones and Manuelli helped move the debate away from pollution being autonomously corrected as wealth increases. López and Mitra (2000) provide a more concrete version of this story with stronger assumptions concerning corruption. They show that corruption does not preclude an EKC but that the turning point will be higher with it than without it. With her provocative title: “Are There Limits to Growth?" Stokey (1998) takes dead aim at the growth-is-bad crowd. She shows that the key to inducing the EKC relationship is being on the right capital accumulation path with respect to pollution control, ${ }^{10}$ and that a pollution tax of the right magnitude, rather than the usual command and control approach, can help ensure this happens.

Many nuances concerning the possibility of an EKC relationship have since been developed, which are covered in detail by Brock and Taylor (2005). One analysis (Andreoni and Levinson 2001) stands out as an instant classic for graduate reading lists due to its theoretical simplicity, the compelling underlying intuition, and its easy-to-explain empirical evidence. Andreoni and Levinson first illustrate their model using a familiar Cobb-Douglas framework. Utility depends on consumption and pollution, with pollution in turn dependent on both consumption levels and pollution control efforts (which reduces consumption). An inverted U-shaped EKC relationship occurs if there are increasing returns to scale in terms of the pollution control effort. One gets a linear relationship if there are constant returns to scale and a U-shaped relationship if there are decreasing returns to scale. Andreoni and Levinson go on to cite empirical evidence from coal-fired power plants and results from large government surveys on U.S. pollution control expenditures by industry, which suggest that increasing returns to scale may be the norm. Their theoretical framework is generic enough to encompass a variety of underlying forces that might give rise to increasing returns, including Jones and Manuelli's (1995) better institutions story, since institutions look like a fixed cost, and Stokey's (1998) story, in which better technology becomes more possible as the scale of production increases. Clearly, increasing returns to scale in pollution control is possible and likely in many cases, although income growth need not be the driving force behind them. Population growth, technological change, or shifts in consumption/trade patterns all work equally well as the source of increasing returns to scale for pollution control.

\footnotetext{
${ }^{10}$ In a strong cautionary note, Arrow et al. (1995) point out that the feedback between ecosystem services and traditional industrial capital stock accumulation is not well understood, and thus, there may not be a clear signal of problems until a threshold is exceeded.
} 


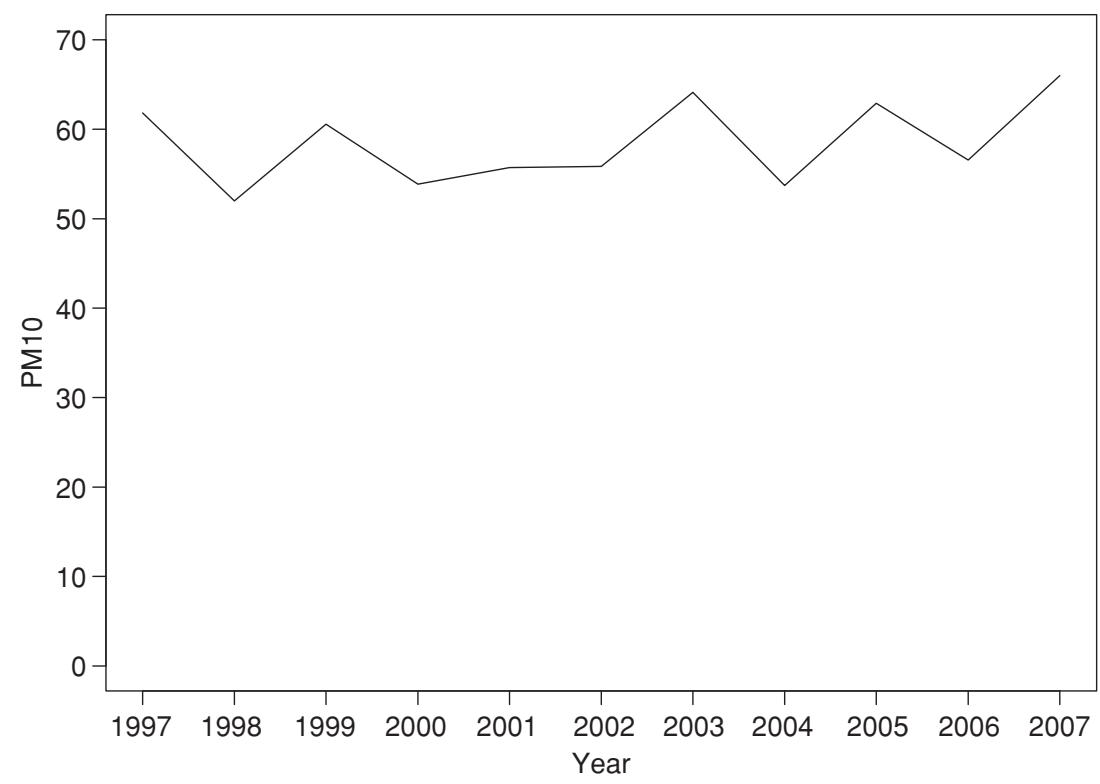

Figure 2 Average annual $P M_{10}$ concentration in Tijuana area of Mexico.

Source: http://www.epa.gov/ttncatcl/cica/sites_sd_e.htm. PM 10 in $\mu \mathrm{g} / \mathrm{m}^{3}$.

\section{Empirical Issues and Evidence}

I turn next to an examination of empirical issues and evidence concerning the existence of an EKC, looking first at evidence from Mexico, followed by a discussion of empirical analyses of the United States, Malaysia, and China.

\section{Focus on Mexico}

The immediate purpose of Grossman and Krueger's (1991) work was to argue that their empirical estimates suggested Mexico was either close to, or at the, turning point where an increase in income would result in a decrease rather than an increase in pollution. Looking at a simple graph (Figure 2) of the average annual $\mathrm{PM}_{10}$ concentration ${ }^{11}$ in the Tijuana area during the 1997-2007 period, which covers most of the relevant history of the NAFTA agreement, ${ }^{12}$ we can see that there has been virtually no change in the ambient $\mathrm{PM}_{10}$ concentrations. However, a casual reading of Grossman and Krueger (1991) suggests that particulates should have fallen substantially, as income increased roughly 20 percent over this time frame.

\footnotetext{
${ }^{11}$ Particulates are generally thought to be the pollutant with the most severe health effects, with smaller particles doing the most harm. The $\mathrm{PM}_{10}$ measure $(10 \mu \mathrm{m})$ is better than the total suspended particulates (TSP) measure used in early EKC studies but not as good as the $\mathrm{PM}_{2.5}$ measure, which is not available for Tijuana over this time period. Fernandez and Carson (2002) provide an overview of NAFTA-related environmental activities in border areas.

${ }^{12}$ Tijuana is one of the wealthiest parts of Mexico and the area most closely linked to the NAFTA agreement, which started in 1994 and was fully implemented by the end of 2007.
} 
Table I Emissions of major air pollutants in Mexico 1990-2000

\begin{tabular}{lccc}
\hline & 1990 & 1995 & $\mathbf{2 0 0 0}$ \\
\hline $\mathrm{CO}$ & 12,297 & 13,268 & 20,595 \\
$\mathrm{CO}_{2}$ & 308,806 & 329,886 & 386,100 \\
$\mathrm{NO}_{x}$ & 1,448 & 1,584 & 2,257 \\
$\mathrm{SO}_{2}$ & 2,106 & 2,251 & 2,934 \\
$\mathrm{VOC}$ & 3,242 & 3,356 & 4,286 \\
\hline
\end{tabular}

Source: WRI (Earthtrends Web site, accessed September 20, 2008); thousands of metric tons.

The other wealthy area, Mexico City, offers a mixed picture. Mexico City has long had some of the worst air pollution in the world. A few air pollutants, most notably lead, which was phased out in gasoline, have declined but most others show little post-NAFTA change. The current struggle to control Mexico City's air pollution is well documented in Molina and Molina (2002) and specific policies have been investigated by economists (e.g., World Bank 2002; Davis 2008).

It is also useful to look at Mexico's total emissions of major air pollutants where the 19901995 period can be thought of as pre-NAFTA and the 1995-2000 period as post-NAFTA (see Table 1). Here there is fairly slow growth in the pre-NAFTA period, but fairly rapid growth for all of the major air pollutants in the post-NAFTA period. This is the opposite of what would have been expected if a strong EKC relationship held.

But this is not the whole story. There are, of course, other confounding variables. Population increased over the time period, albeit at a slower rate than it did previously, producing flatter but still increasing per capita growth in the major air pollutants. Gallagher (2004) and Stern (2007) provide comprehensive reviews of the environmental impacts of NAFTA and reach similar conclusions: that much of what transpired was the continuation of long-term trends and the convergence over time of Canada, Mexico, and the United States in a technological sense, which to a large degree cannot be clearly tied to NAFTA. Surprisingly, Gallagher finds that increased income in Mexico did not result in more government spending on environmental policies. Stern notes "regarding air pollution and energy efficiency none of the more extreme predictions [good or bad] of the outcomes of NAFTA have come to fruition to date."

Grossman and Krueger (1991) did not explicitly study Mexico City's air pollution because it was not included in the GEMS database of pollutants and cities. In retrospect, it would have been possible to put together some type of dataset, as there have long been efforts to monitor and address air pollution in Mexico City (e.g., Alvarez 1987) and along the U.S.-Mexican border (e.g., Applegate and Bath 1974). Grossman and Krueger's big assumption was that something could be learned about the pollution impact of increasing income in Mexico (due to NAFTA) from a reduced-form equation, but using data with no direct connection to Mexico. It was this assumption that gave the EKC its broad policy relevance. ${ }^{13}$

\footnotetext{
${ }^{13}$ Grossman and Krueger (1991) did perform a separate analysis using the U.S. input-output tables and associated pollution to ask what would happen if particular sectors of the U.S. economy shifted to Mexico as a result of NAFTA. While not directly part of the EKC literature, it was seen as supporting the general EKC result. Hettige, Lucas, and Wheeler (1992) extended this type of analysis to a set of eighty countries and found an inverted U-shaped curve with respect to output per unit of GDP, although they found that the pollution intensity of manufacturing steadily rose with income.
} 


\section{A Detour to the United States}

Much of the initial empirical critique of the EKC view of the world revolved around the fact that relatively few developing countries were used in the Grossman and Krueger (1991) sample. Selden and Song (1994), for instance, showed that there were twenty-two high, six middle, and only two low-income countries in the sample, not a lot of data from which to identify a nonlinear relationship with respect to income. Further, it became clear that the data were not as comparable across countries as one might hope. In an early influential critique, Stern, Common, and Barbier (1996) note that the pollution data used in environmental Kuznets curve studies are "notoriously patchy in coverage and/or poor in quality." The World Resource Institute (WRI) guides $(1994,1996)$, which provide air pollution data for some EKC studies, warned: "These data on anthropogenic sources should be used carefully. Because different methods and procedures may have been used in each country, the best comparative data may be time trends within a country." Even this warning was probably insufficient, as there are large differences in some estimates in the 1994-1995 and 1996-1997 WRI guides for the same pollutant in the same country and year.

Carson, Jeon, and McCubbin (1997) found one way out of this dilemma by looking at only one side of the inverted U using data from the fifty U.S. states. This substantially increased the sample size and resolved data comparability issues since USEPA measured pollution the same way in every state. Further, there was a reasonable range in per capita income, with Connecticut's being more than twice that of Mississippi. Finally, the United States was on the downside of any turning points that had been found for air pollutants other than $\mathrm{CO}_{2}$, so there was a strong expectation that air pollution would monotonically decline with income.

Using a 1990 cross-section of state-level point-source emissions for air toxics, $\mathrm{CO}, \mathrm{NO}_{x}$, $\mathrm{SO}_{2}$, volatile organic compounds (VOC), and $\mathrm{PM}_{10}$, Carson, Jeon, and McCubbin (1997) found that per capita emissions of all pollutants monotonically declined as income increased. Similar results were shown for $\mathrm{CO}_{2}$ emissions for point and mobile sources combined at the state level and for $\mathrm{PM}_{10}$ emissions from a sample of 1,748 counties. The most striking finding across all of the air pollutants was that the high-income states uniformly had low per capita emissions while the per capita emissions from lower-income states were highly variable. The results were shown to be robust to the use of different statistical techniques and functional forms.

Though the Carson, Jeon, and McCubbin (1997) results provide support for the EKC hypothesis, their analysis of a panel dataset of air toxics emissions over a six-year period (1989-1994) showed no relationship between changes in income and per capita emissions. However, states with high initial incomes were associated with larger reductions in per capita emissions over the time period, and the same was true of states with high initial per capita emissions levels. Put simply, the wealthy states continued to reduce emissions, irrespective of changes in income levels, as did dirty states. These results are consistent with the strong regulatory structure established by higher-income states and a technology explanation whereby it is cheaper to reduce pollution if there is lots of it.

I now turn to a study by List and Gallet (1999) that uses a USEPA dataset of per capita $\mathrm{SO}_{2}$ and $\mathrm{NO}_{x}$ emissions at the state level from 1929 to 1994. Data before 1985 are based on estimates of production activities at the state level. With a much longer time series plus real income levels ranging from just over $\$ 1000$ to over $\$ 20,000$, List and Gallet are able to 
estimate individual EKC models for each state for the two pollutants. They find EKC-like turning points, but they appear to be driven by substantially different processes across states. In fact, List and Gallet find that turning points between states often differ by a factor of two or three, and in some instances, an order of magnitude. Thus any attempt to force the different states into a single underlying process can be statistically rejected. These results reject a core concept that lies behind much of the EKC work: that after allowing for state-level fixed-effect terms, a common process drives the income-pollution relationship. Finally, one would expect a priori that different U.S. states would be much more alike than different countries. Thus, these results also cast doubt on what is really being learned from the "average" parameter estimates in the typical cross-country panel dataset and whether those parameters have any relevance for what is likely to happen in an individual country. Given List and Gallet's result, it should be no surprise that it is easy to reject statistical tests of whether OECD and nonOECD countries can be pooled, as is typical in the standard EKC regression (Cole 2005). In retrospect, a clear distinction should probably have been drawn between a weak conceptual version of the EKC as an inverted U-shaped curve for a particular political jurisdiction, which is largely supported by the empirical evidence, and the much stronger empirically actionable version with a common EKC income-pollution relationship across political jurisdictions, which is not supported by the evidence.

Completing our tour of the United States is Aldy (2005), who looks at estimated $\mathrm{CO}_{2}$ emissions (based on fossil fuel use) across the forty-eight continental U.S. states from 1960 to 1999. Consistent with Carson, Jeon, and McCubbin's (1997) cross-sectional result, Aldy finds evidence supporting an EKC relationship for the United States. With a much wider income range, Aldy can also estimate reasonably precise turning points, and, like List and Gallet (1999), he finds evidence that different states follow substantially different income-pollution paths. Aldy examines the dynamic properties of the time series and finds them problematic (an issue examined later) and quite different across the states. Perhaps the paper's most interesting result is that a consumption-based per capita emissions relationship has a turning point about 40 percent higher than a production-based estimate. This means that higherincome states are effectively importing their energy consumption from lower-income states. This raises questions about what the EKC relationship of interest actually is, an issue that will be examined later.

\section{Side Trips to Malaysia and China}

Vincent (1997) looked at a panel dataset of seventeen Malaysian states and six pollution measures (TSP and five water pollutants) from the late 1970s through 1991. These data are arguably of higher quality than data available from most developing countries. In no case does he find evidence of an inverted U-shaped pattern even though the change in income encompassed typically estimated turning points. Malaysia's experience cannot be easily reconciled with the predictions concerning income-pollution relationships in Grossman and Krueger (1991); Shafik and Bandyopadhyay (1992); and Selden and Song (1994). In fact, some pollutants predicted to increase actually decreased, while pollutants predicted to decrease increased. Even when the direction of change was correctly predicted, the magnitude of the change was substantially off. Various policy measures taken by the Malaysian government 
seem to provide an explanation for the observed patterns. Vincent (1997) succinctly summarizes his conclusion from this analysis:

The lack of evidence of EKCs in Malaysia does not prove that EKCs do not exist anywhere. It does indicate, however, that policymakers in developing countries should not assume that economic growth will automatically solve air and water pollution problems.

Turning to China, Auffhammer and Carson (2008) examine forecasting of $\mathrm{CO}_{2}$ emissions, a critical feature in any discussion of climate policy. They use provincial-level per capita emissions from 1985-2004, with the national estimate obtained by aggregating across provinces. There is considerable income variation across the Chinese provinces, both temporally and spatially, making China an ideal case to study. Given past estimates of turning points for $\mathrm{CO}_{2}$, all of the observations should be on the upside of any inverted U. Auffhammer and Carson find a highly significant EKC relationship. ${ }^{14}$ However, the effect, while still important, diminishes considerably when lagged emissions are included as a predictor. Auffhammer and Carson argue that using lagged emissions is consistent with emissions being driven to a large degree by the technological efficiency of long-lived capital stock (e.g., coal-fired power plants) and show that the size of the provincial-specific lag has very substantial implications for the path of a province's $\mathrm{CO}_{2}$ emissions. The lag structure also eliminates some of the time-series issues discussed below. Auffhammer and Carson move away from the association/causality framework inherent in most EKC papers to an out-of-sample forecasting performance perspective. They also include a quadratic income term, which is clearly an improvement over models with only a linear term.

\section{Will the Real EKC Please Stand Up?}

The discussions above raise a subtle question: what is the dependent variable on which the $\mathrm{EKC}$ is defined? There has been a plethora of EKC definitions in both the theoretical literature and empirical work. Aldy's (2005) work uses two distinct definitions of the EKC relationship that operationalize the concern that all that the richer areas have done is to offload dirtier production to poorer areas. Other definitions have been introduced implicitly, without making any distinctions between them. The original Grossman and Krueger (1991) work used ambient quality measures in defining an EKC relationship. Later papers, however, often worked with per capita emissions and, in still other cases, with total measures like the quantity of land deforested. It is possible to make a reasonable case for, and against, any of these definitions.

Ambient quality measures have the closest tie to social welfare but are inherently impacted by population and physical conditions such as the presence of mountains and climate. ${ }^{15}$ Per capita measures are easily interpreted in terms of how a resource is being used or how much pollution is being created on average by each person. Such measures are popular because they are easily compared across countries and can often be estimated from production data.

\footnotetext{
${ }^{14}$ Using a flexible smoothing spline approach similar to Schmalensee, Stoker, and Judson (1998) suggests a flattening out of income rather than a downturn in the range observed.

${ }^{15}$ Most of these effects are proxied for using fixed effects. Cropper and Griffiths (1994), who examine deforestation, are one of the few papers that try to separate out the independent effect of population growth.
} 
The problem, of course, is that such measures don't necessarily bear any relationship to individual utility. Per capita measures like the popular environmental footprint statistics ignore the ability of the environment to cope with the imposed externality. For example, two cities with the same per capita $\mathrm{SO}_{2}$ emissions may have radically different exposure levels. Per capita measures have weak ties to most theoretical EKC models, which assume that at some point it is likely to be advantageous to trade off some income for better environmental quality. ${ }^{16}$ Aldy's production versus consumption per capita measures drive this point home further, as once trade is allowed, it is possible to consume goods without experiencing externalities associated with their production (Suri and Chapman 1998).

For issues like deforestation, which is not the result of widely shared industrial processes, it is natural to think of the total amount of forested land. Hence, the tie to population is much more tenuous. In this case, it may be useful to distinguish between stocks, such as the percent of the land forested, and flows, such as the rate of deforestation in a particular year (Shafik and Bandyopadhyay 1992).

\section{Econometric Issues}

The econometric foundations of EKC models have long been both suspect and fragile. ${ }^{17}$ A prime example of the econometric problems with the EKC is illustrated in Harbaugh, Levinson, and Wilson (2002), who examine an extended version of the GEMS dataset originally used by Grossman and Krueger (1991). Their analysis added several more years on each end of the GEMS dataset, corrected data values, and filled in a considerable amount of missing data. They conclude:

The evidence for an inverted $U$ is much less robust than previously thought. We find the location of the turning points, as well as their very existence, are sensitive to both slight variation in the data and to reasonable permutations of the econometric specification.

The EKC debate can also be seen as being part of the much larger debate about the crosscountry growth equation that took center stage in economics in the late 1980s and early 1990s (e.g., Barro 1991; Mankiw, Romer, and Weil 1992). The possibility that economists could predict economic growth as a function of a few key input variables clearly captured the imagination and attention of the profession. However, the cracks soon became evident. As Levine and Renelt (1992) put it in an early systematic and highly cited review of the evidence from an econometric perspective:

A vast literature uses cross-country regressions to search for empirical linkages between long-run growth rates and a variety of economic policy, political, and institutional indicators. This paper examines whether the conclusions from existing

\footnotetext{
${ }^{16}$ This trade-off typically requires government action, although Pfaff, Chaudhuri, and Nye (2004) use a household-production function to show that Pakistani households switch to cleaner fuels as their income increases.

${ }^{17}$ This section draws heavily upon Stern's (2004) detailed and highly critical overview of many of the specific econometric issues related to the EKC.
} 
studies are robust or fragile to small changes in the conditioning information set.

We find that almost all results are fragile.

Note the striking similarity between the conclusions of Harbaugh, Levinson, and Wilson (2002) and Levine and Renelt (1992).

\section{Representativeness of Samples and Comparability of Pollution Measures}

The major econometric issue that dominated the early EKC discussions was the representativeness of the samples used and the comparability of the pollution measure used. At the heart of this issue is the question of what can really be learned from the regression models estimated. The most visible problem was the relative lack of developing countries in the GEMS data underlying much of the early EKC work. But as Stern (2004) points out, the deeper problem is that statistical tests usually reject random effects specifications due to the correlation between the random effects and the included covariates. The implication is that while the fixed-effects model may be consistent for the sample on which it is estimated, the parameter estimates cannot be generalized to another sample. This makes suspect any EKC model that is missing the countries of interest. Ironically, the fixed-effects models estimated on U.S. state-level data or their equivalent in other countries are fine because all of the political units of interest are included.

The major reason for including a particular set of countries in most EKC studies has been the availability of an indicator of interest measured in a reasonably comparable way. As Grossman and Krueger (1995) explain:

The main contribution of the present paper is that it employs reliable data and a common methodology to investigate the relationship between the scale of economic activity and environmental quality for a broad set of environmental indicators. We attempt to include in our study all of the dimensions of environmental quality for which actual measurements have been taken by comparable methods in a variety of countries.

They go on to note that they are using all of the GEMS air- and water-quality data. At some level, the deficient representation of developing countries in the GEMS dataset was symptomatic of the lack of interest in environmental issues in those countries at the time. More importantly, without a comprehensive monitoring network, even measures of ambient quality across cities taken using comparable equipment are suspect. This issue was recognized in early U.S. studies (e.g., Lave and Seskin 1977) and eventually led to monitoring schemes with spatial placement of monitors designed to gather comparable data based on population exposure (Auffhammer, Bento, and Lowe 2009).

\section{The Focus on $\mathrm{SO}_{2}$}

Some measurement issues related to the GEMS data concerning both coverage and data quality can be avoided if estimates of $\mathrm{CO}_{2}$ and $\mathrm{SO}_{2}$ emissions, calculated from fuel-consumption data using conversion ratios, are used. Because $\mathrm{CO}_{2}$ is a global rather than a local externality, it was simple to explain why it showed, at best, a weak EKC relationship. Thus, $\mathrm{SO}_{2}$ became the poster child for the EKC relationship. 
In retrospect, the emphasis on $\mathrm{SO}_{2}$ may have been misplaced for several reasons, and it is unfortunate that some of the most sophisticated analyses (e.g., Copeland and Taylor 2003) have been directed to this pollutant. $\mathrm{SO}_{2}$ 's human health impacts relative to fine particulates or ozone are small. Stern's (2006) analysis using emissions data from a large number of countries shows that $\mathrm{SO}_{2}$ levels have fallen over time with advances in technology across the world and with greater rapidity in developed countries. His estimates still suggest an EKC relationship, but the turning point is now above fifty thousand dollars-an order of magnitude higher than found in some of the earlier studies. Deacon and Norman (2006) look at within-country $\mathrm{SO}_{2}$ data for twenty-five countries using 1970-1992 GEMS data. They show there is an income- $\mathrm{SO}_{2}$ relationship consistent with an EKC in more countries than would be expected by chance. (Surprisingly, the two other common GEMS air pollutants, smoke and particulates, fail even this very weak test.) However, this relationship appears to be driven almost entirely by increasing incomes and decreasing $\mathrm{SO}_{2}$ concentrations in wealthy democracies. Deacon and Norman conduct further analysis allowing income and purely trend-driven factors to explain within-country pollution patterns during the 1970s and 1980s. When they do find a separable role of income, it is generally insignificant and, "where significant, its effect is not consistent with predictions of the EKC hypothesis."

\section{Data Quality Issues}

Problems with data quality and nonrandom/incomplete samples plague much of economics, so there is nothing unique about the EKC experience. Most good papers are upfront about the problem. As noted by Panayotou (1997): "Data on environmental problems are notoriously patchy in coverage and/or poor in quality. The only available data are not necessarily appropriate for testing the EKC hypothesis, estimating its parameters, and drawing inferences about future trends." Having made this acknowledgment, researchers then fixed as much of the problem as possible and proceeded to estimate the best model they could. Seeing a clear association between income and pollution that was strikingly different from the linear projection typically assumed, it was natural to ask what was behind the reduced-form black box. This question was most prominently put forward by Panayotou $(1993,1997)$ in early work employing cross-sectional data in the 1990s and pursued by a number of other authors (e.g., Stern, Common, and Barbier 1996; Perman and Stern 2003). Getting inside the black box implied either finding the policy levers that reduced pollution or showing causality from income to pollution. Panayotou followed the first course, which is discussed below.

\section{Role of Other Covariates}

The earliest EKC research (e.g., Grossman and Krueger 1991; Shafik and Bandyopadhyay 1992; Selden and Song 1994) was concerned with the influence of variables other than income, such as population density and trade indicators, either because they were possible alternative explanations to income or because they increased the precision of the estimates. To these Panayotou (1997) sought to add something more clearly exogenous and likely correlated with pollution control policy. His choice was the quality of institutions related to the enforcement 
of contracts, which is now a standard political variable. ${ }^{18}$ This variable is shown to shift the EKC relationship up and down by a considerable amount.

Other papers are supportive of some type of policy explanation. Controlling for other variables, Grossman and Krueger's (1991) original work showed communist countries were dirtier with respect to $\mathrm{SO}_{2}$. Torras and Boyce (1998) showed that in low-income countries, improving political rights and civil liberties or the equality of the income distribution was typically associated with lower pollution levels in an EKC. They conclude: "The estimated effects of per capita income on pollution generally weaken once we account for inequality effects, but they do not disappear altogether." Barrett and Graddy (2000) use some of the same variables as Torras and Boyce, but a broader range of GEMS pollutants and specifications. They start by demonstrating high correlations between various political/civil rights variables and income across countries, which is clearly problematic for showing separate effects for political variables and income. Their empirical results, while similar in some ways to Torras and Boyce, are much more mixed, as some pollutants don't follow the same pattern as the commonly examined GEMS air pollutants. In puzzling over their results, Barrett and Graddy (2000) note: "Research that links the inverted-U to actual policies would seem to be badly needed." Deacon and Saha (2006) survey the now fairly sizeable literature on public goods provision under different political conditions and find a robust association between the provision of environmental goods and more democratic systems. The major caveat with pushing this line too far is that many of the same issues with the EKC exist when looking at the role of political variables in the provision of environmental goods. Fundamentally, the political story is more satisfying as it is about how public preferences get translated into changes in environmental quality as income increases. However, as McConnell (1997) has shown from a theoretical vantage point, having positive income elasticity for environmental quality is neither necessary nor sufficient for an EKC relationship, making interpretation of empirical results difficult.

\section{Difficulty of Showing Causality}

A more fundamental problem is the need to show causality between income and the environmental variable of interest. This problem plagues most cross-country reduced-form models looking at growth and is thus not unique to looking at the underpinnings of a possible EKC relationship. One definition of causality, based on Granger (1980) and frequently used by economists, is whether a change in one variable occurs before changes in another variable and helps to predict that variable. While this definition is intuitive, it is not particularly strong. Moreover, there are a number of standard econometric issues involved, including the specification of the data-generating process and what covariates to condition on. Further issues arise if the variables of interest are not stationary from a time-series perspective and if panel data are used.

Recently, tests using the Granger definition of causality (e.g., Perman and Stern 2003) have been performed. The results are problematic, as key variables such as income can often be shown to be integrated (i.e., nonstationary), suggesting that $\mathrm{EKC}$ regressions may produce

\footnotetext{
${ }^{18}$ The quality of bureaucracy performed similarly, which is expected given its high correlation with the contract variable.
} 
spurious results. In some cases, Granger causality implies that variables must move together in the statistical sense of being cointegrated, but there is little statistical support for the presence of cointegrated relationships consistent with an EKC. With few exceptions, early work on the EKC did not take the time-series structure of the data seriously. Yet the whole conceptual notion behind the EKC was a long-run equilibrium relationship in which increases in income would lead, after the EKC turning point, to less pollution being generated.

\section{Further Issues: Functional Form for Income and Pollution Havens}

One could take up any number of other econometric issues with the EKC or look at specific pollutants/amenities that have been examined, but this would require more space than is available here. However, two issues should be briefly mentioned. The first is the common practice of fitting a cubic function to income as a generalization of the EKC's standard quadratic form in income. Since the cubic term is sometimes significant, there has been the tendency to interpret this result as suggesting that environmental conditions eventually take a turn for the worse as income increases. More likely there is simply a flattening of the income-pollution relationship that is not approximated well by a quadratic function.

The second issue is the concept of pollution havens, which drove some of the original concerns over free-trade agreements, since one obvious source of an EKC relationship is for a wealthy country to transfer its dirty industry to a poor country. Most influential was an early empirical paper by Tobey (1990), suggesting that the stringency of environmental regulation had little impact on trade patterns. The commonly advanced rationale is that pollution control costs are usually small relative to total cost, and that multinational firms that run similar operations across countries do not want to be seen as running a dirty operation in developing countries. Since the Tobey study, a number of pollution haven effects have been found, but these have usually been small or temporary except for a pattern of transferring manufacturing from developed to developing countries, for which there are other potential causes. Cole (2004) provides a literature review and an empirical analysis consistent with this view. Levinson and Taylor (2008), however, have recently shown how unobserved heterogeneity, endogeneity, and aggregation issues tend to bias the standard analysis against finding a pollution haven effect. Their empirical results using data from Canada, Mexico, and the United States suggest that pollution control expenditures have fairly sizeable and economically meaningful impacts on trade patterns.

\section{Some Concluding Thoughts on the EKC}

As we near the end of almost two decades of searching for EKCs, it is useful to reflect on what has been learned. Grossman and Krueger $(1991,1995,1996)$ sought to demonstrate three points. First, increases in income were not automatically associated with increased pollution. Second, freer trade would not necessarily make pollution worse. Third, a free-trade agreement with Mexico would make the pollution situation in Mexico and the United States better, not worse. On the first two points, Grossman and Krueger have clearly succeeded in changing the views of most economists, and the bulk of the empirical evidence supports them. On the third point, the counterfactual is always hard to know. Our cursory examination of the evidence suggests that Mexico is at best treading water with respect to pollution. However, 
this may not be as bad as it appears. With a large increase in economic output and population, it would have been easy to forecast the much worse path predicted by many NAFTA critics.

On the main message taken from Grossman and Krueger's work by the economics profession-that trade and higher income levels would make for a better environmentthe supporting evidence is scant, fleeting, and fragile. Desperately sought, causality has yet to be conclusively found. Ultimately, the dogged pursuit of ever better empirical estimates has not revealed a clear causal income-pollution relationship although, as Auffhammer and Carson (2008) show, there may be some short- to medium-term gain from using income in a forecasting equation. However, the finding that a negatively signed quadratic income term improves forecasting performance is actually much more damaging to the IPAT view of the world, where pollution is always increasing monotonically with per capita income and growing affluence is still seen as the major cause of deteriorating environmental conditions. ${ }^{19}$ There is little evidence that stopping growth would improve pollution levels. Instead, there is robust evidence that pollution levels typically fall at high-income levels.

The difficulty is finding a common underlying process at work and linking specific changes in income to specific changes in pollution on the timescale of a few years. It may be possible to resurrect a much looser view of the reduced-form EKC where different political jurisdictions can follow very different EKC paths for the same pollution indicator; moreover, income affects this indicator on a much longer timescale through a diffuse set of paths. Such a formulation, however, is not very useful for policy and, for all practical purposes, is close to being empirically untestable from a causal perspective.

Dasgupta et al. (2002) put forth a positive but realistic view of what remains of the original EKC story:

The environmental Kuznets curve posits an inverted-U relationship between pollution and economic development. Pessimistic critics of empirically estimated curves have argued that their declining portions are illusory, either because they are cross-sectional snapshots that mask a long-run "race to the bottom" in environmental standards, or because industrial societies will continually produce new pollutants as the old ones are controlled. However, recent evidence has fostered an optimistic view by suggesting that the curve is actually flattening and shifting to the left. The driving forces appear to be economic liberalization, clean technology diffusion, and new approaches to pollution regulation in developing countries.

This is, however, a far cry from a statement about an income-pollution relationship. Indeed, it could be recast as a statement about good government and technology feeding into an optimistic view of the IPAT equation. It subtly echoes the original economic critique that societal choice is missing from the mechanistic IPAT view of the world. Income can influence pollution levels, but it may do so in slow and subtle ways through its influence on other factors such as improving institutions. In practice, it may be difficult to separate out growth and the diffusion of clean technology. One potential solution is to think of the EKC not in terms of its typical reduced-form representation, but in terms of a structural

\footnotetext{
${ }^{19}$ One sign that the EKC side may have won the long-term conflict is that some proponents of the IPAT framework have modified it to allow for the possibility that income could have a beneficial effect (e.g., Waggoner and Ausubel 2002; York, Rosa, and Dietz 2003).
} 
model where income influences demand and supply factors that directly influence pollution (Kolstad 2006).

A more pessimistic view of the situation is that belief in an autonomous EKC relationship engendered an unfounded optimism that growth by itself would be helpful for the environment. As a result there was a lost decade or more during which environmental economists failed to focus on other potential driving forces behind changes in environmental quality within a country. The debate over the income-pollution relationship allowed us as a profession to take our eye off what really mattered. First, and perhaps foremost, it made it easy to believe that developing countries should be able to ignore their environmental problems until they develop and become wealthier. But we now know that developing countries can take many actions (Dasgupta et al. 2002) to improve their environmental conditions and that those actions can have enormously positive implications for societal welfare. Second, as a group, we largely ignored the role of population and technology, the other two factors in the IPAT equation. Third, for every dozen EKC papers, there might be one that seriously looked at how changes in the regulatory structures and incentive systems in place across different political jurisdictions could be used to improve environmental quality in places where population is increasing, income is improving, and technology from around the world is potentially available. What is needed now and in the future is work identifying factors that can translate some of the increased income from growth into improved environmental quality.

\section{References}

Aldy, J. E. 2005. An environmental Kuznets curve analysis of U.S. state-level carbon dioxide emissions. Environment and Development Economics 14: 48-72.

Alvarez, H. B. 1987. La Contaminación del Aire en Mexico. Mexico City: Universo Veintiuno.

Andreoni, J., and A. Levinson. 2001. The simple analytics of the environmental Kuznets curve. Journal of Public Economics 80: 269-86.

Applegate, H. G., and C. R. Bath. 1974. Air pollution along the United States-Mexico border. El Paso:

Texas Western Press.

Arrow, K., B. Bolin, R. Costanza, P. Dasgupta, C. Folke, C. S. Hollings, B. O. Jansson, S. Levin, K. G. Mäler, C. Perrings, and D. Pimentel. 1995. Economic growth, carrying capacity and the environment. Science 268: 520-21.

Auffhammer, M., A. M. Bento, and S. E. Lowe. 2009. Measuring the effects of environmental regulations: The critical importance of a spatially disaggregated analysis. Journal of Environmental Economics and Management 58: 15-26.
Auffhammer, M., and R. T. Carson. 2008. Forecasting the path of China's $\mathrm{CO}_{2}$ emissions using province level information. Journal of Environmental Economics and Management 55: 229-47.

Barrett, S., and K. Graddy. 2000. Freedom, growth and the environment. Environment and Development Economics 5: 433-56.

Barro, R. J. 1991. Economic growth in a cross section of countries. Quarterly Journal of Economics 106: 407-44.

Bartlett, B. 1994. The high cost of turning green. Wall Street Journal, September 14.

Beckerman, W. 1992. Growth and the environment: Whose growth? Whose environment? World Development 20: 481-96.

Brock, W. A., and M. S. Taylor. 2005. Economic growth and the environment: A review of theory and empirics. In Handbook of Economic Growth, vol. 1B, ed. P. Aghion and S. N. Durlauf. Amsterdam: North-Holland. 
Carson, R. T., Y. Jeon, and D. McCubbin. 1997. The relationship between air pollution and emissions: U.S. data. Environment and Development Economics 2: 433-50.

Cavlovic, T., K. Baker, R. Berrens, and K. Gawande. 2000. A meta-analysis of the environmental Kuznets curve studies. Agriculture and Resource Economics Review 29: 32-42.

Cole, M. 2004. Trade, the pollution haven hypothesis and environmental Kuznets Curve: Examining the linkages. Ecological Economics 48: 71-81.

2005. Re-examining the pollution-income relationship: A random coefficients approach. Economic Bulletin 14: 1-7.

Commoner, B.. 1972. The environmental cost of economic development. In Population, environment and resources. Washington, DC: U.S. Government Printing Office.

Copeland, B., and S. Taylor. 2003. Trade and the Environment. Princeton, NJ: Princeton University Press.

Cropper, M., and C. Griffiths. 1994. The interaction of population growth and environmental quality. American Economic Review 84: 250-54.

Daly, H. 1993. Perils of free trade. Scientific American 269: 50-7.

Dasgupta, S., B. Laplante, H. Wang, and D. Wheeler. 2002. Confronting the environmental Kuznet's curve. Journal of Economic Perspectives 16: 147-68.

Davis, L. 2008. The effect of driving restrictions on air quality in Mexico City. Journal of Political Economy 116: 38-81.

Deacon, R. T., and C. S. Norman. 2006. Does the environmental Kuznets curve describe how individual countries behave? Land Economics 82: 291-315.

Deacon, R. T., and S. Saha. 2006. Public goods provision under dictatorship and democracy: A survey. In The companion in public economics: Empirical public economics, ed. A. F. Ott and R. J. Cebula. Northhampton, MA: Edward Elgar Publishing, 2006.

De Bruyn, S. M., J. C. J. M. van den Bergh, and J. B. Opschoor. 1998. Economic growth and emissions: Reconsidering the empirical basis of environmental Kuznets curve. Ecological Economics 25: 161-75.
Dinda, S. 2004. Environmental Kuznets curve hypothesis: A survey. Ecological Economics 49: 431-55.

Ehrlich, P. 1968. The population bomb. New York: Ballentine.

Ehrlich, P., and J. Holden. 1971. Impact of population growth. Science 171: 1212-17.

Fernandez, L., and R. T. Carson, eds. 2002. Both sides of the border: Transboundary environmental management issues facing Mexico and the United States. Norwell, MA: Kluwer Academic Publishers.

Frank, R. H., and B. S. Bernanke. 2005. Principles of economics, 3rd ed. New York: McGraw-Hill.

Gallagher, K. P. 2004. Free trade and the environment: Mexico, NAFTA, and beyond. Palo Alto, CA: Stanford University Press.

Granger, C. W. J. 1980. Testing for causality: A personal viewpoint. Journal of Economics Dynamics 2: 329-52.

Grossman, G. M, and A. B. Krueger. 1991. Environmental impacts of a North American Free Trade Agreement. NBER Working Paper 3914. Cambridge, MA: National Bureau of Economic Research.

1995. Economic growth and the environment. Quarterly Journal of Economics 110: 353-77.

1996. The inverted U: What does it mean? Environment and Development Economics 1: 119-22.

Harbaugh, W. T., A. Levinson, and D. M. Wilson. 2002. Reexamining the empirical evidence for an environmental Kuznets curve. Review of Economics and Statistics 84: 541-51.

Hettige, H., R. Lucas, and D. Wheeler. 1992. The toxic intensity of industrial production: Global patterns, trends, and trade policy. American Economic Review 82: 478-81.

Holtz-Eakin, D., and T. M. Selden. 1995. Stoking the fires? $\mathrm{CO}_{2}$ emissions and economic growth. Journal of Public Economics 57: 85-101.

John, A., and R. Pecchenino. 1994. An overlapping generation model of growth and the environment. Economic Journal 104: 1393-410.

Jones, L., and R. Manuelli. 1995. A positive model of growth and pollution controls. National Bureau of Economic Research Working Paper W5202.

Kolstad, C. D. 2006. Interpreting estimated environmental Kuznets curves for greenhouse 
gases. Journal of Environment and Development 15: 42-49.

Kneese, A., and R. Ridker. 1972. Predicament of mankind. Washington Post March 2, 81-82.

Lave, L. B., and E. P. Seskin. 1977. Air pollution and human health. Baltimore: Johns Hopkins University Press.

Levine, R., and D. Renelt. 1992. A sensitivity analysis of cross country growth equations. American Economic Review 82: 942-963.

Levinson, A. 2002. The ups and downs of the environmental Kuznets curve. In Recent advances in environmental economics, ed. J. List and A. de Zeeuw. Northhampton, MA: Edward Elgar Publishing, 2002.

Levinson, A., and S. Taylor. 2008. Unmasking the pollution haven effect. International Economic Review 49: 223-54.

List, J., and C. Gallet. 1999. The environmental Kuznets curve: Does one size fit all. Ecological Economics 31: 409-23.

López, R. 1994. The environment as a factor of production: The effects of economic growth and trade liberalization. Journal of Environmental Economics and Management 27: 163-84.

López, R., and S. Mitra. 2000. Corruption, pollution, and the Kuznets environment curve. Journal of Environmental Economics and Management 40: 137-50.

Mankiw, G., D. Romer, and D. Weil. 1992. A contribution to the empirics of economic growth. Quarterly Journal of Economics 107: 407-37.

Meadows, D. H., D. L. Meadows, J. Randers, and W. H. Behrens. 1972. The limits to growth: Report: A report to the Club of Rome's project on the predicament of mankind. New York: Universe Books.

McConnell, K. E. 1997. Income and the demand for environmental quality. Environment and Development Economics 2: 383-99.

Molina, L. T., and M. J. Molina, eds. 2002. Air quality in the Mexico megacity: An integrated assessment. Boston: Kluwer.

Nordhaus, W. D. 1973. World dynamics: Measurement without data. Economic Journal 83: 1156-83.

Panayotou, T. 1993. Empirical tests and policy analysis of environmental degradation at different stages of economic development. Working Paper
WP238, Technology and Employment Programme. Geneva: International Labor Office.

1997. Demystifying the environmental

Kuznets curve: Turning a black box into a policy tool. Environment and Development Economics 2: 465-84.

Perman, R., and D. I. Stern. 2003. Evidence for the panel unit root and cointegration tests that the environmental Kuznets curve does not exist. Australian Journal of Agricultural Economics 47: 325-47.

Pethig, R. 1976. Pollution, welfare, and environmental policy in the theory of comparative advantage. Journal of Environmental Economics and Management 2: 160-69.

Pfaff, A. S. P., S. Chaudhuri, and H. L. M. Nye.

2004. Household production and the environmental Kuznets curve. Environmental and Resource Economics 27: 187-200.

Russell, C. S. 2001. Applying economics to the environment. Oxford: Oxford University Press.

Schmalensee, R., T. M. Stoker, and R. A. Judson. 1998. World carbon dioxide emissions: 1950-2050. Review of Economics and Statistics 80: 15-27.

Selden, T. M., and D. Song. 1994. Environmental quality and development: Is there an environmental Kuznet's curve for air pollution? Journal of Environmental Economics and Management 27: 147-62.

1995. Neoclassical growth, the J curve for abatement and the inverted $U$ for pollution. Journal of Environmental Economics and Management 29: 162-68.

Shafik, N. 1994. Economic development and environmental quality: An econometric analysis. Oxford Economic Papers 46: 757-73.

Shafik, N., and S. Bandyopadhyay. 1992. Economic growth and environmental quality: Time series and cross country evidence. World Development Working Paper WPS 904. Washington, DC: World Bank.

Solow, R. M. 1973. Is the end of the world at hand? Challenge 16: 39-50.

Stern, D. 2004. The rise and fall of the environmental Kuznets curve. World Development 32: 1419-39.

2006. Reversal of the trend in global anthropogenic sulfur emissions. Global Environmental Change 16: 207-20. 
Stern, D. 2007. The effect of NAFTA on energy and environmental efficiency in Mexico. Policy Studies Journal 35: 291-322.

Stern, D. I., M. S. Common, and E. B. Barbier. 1996. Economic growth and environmental degradation: The environmental Kuznets curve and sustainable development. World Development 24: 1151-60.

Stokey, N. 1998. Are there limits to growth? International Economic Review 39: 1-31.

U.S. Council of Economic Advisors. 1999. A new set of international comparisons of real product and price level estimates for 130 countries, 1950-1985. Review of Income and Wealth 34: 1-26.

Suri, V., and D. Chapman. 1998. Economic growth, trade and energy: Implications for the environmental Kuznets curve. Ecological Economics 25: 195-208.

Sutton, J. D., ed. 1988. Agricultural trade and natural resources: Discovering the critical linkages. London: Rieumer.

Tobey, J. B. 1990. The effects of domestic environmental policies on patterns of world trade: An empirical test. Kyklos 43: 191-209.

Torras, M., and J. K. Boyce. 1998. Income inequality and pollution: A reassessment of the environmental Kuznets curve. Ecological Economics 25: 147-60.

U.S. Council of Economic Advisors. 1999. Economic report of the president. Washington, DC: U.S. Government Printing Office.
Vincent, J. R. 1997. Testing for environmental Kuznets curves within a developing country. Environment and Development Economics 2: 417-31.

Waggoner, P. E., and J. H. Ausubel. 2002. A framework for sustainability science: A renovated IPAT identity. Proceedings of the National Academy of Sciences 99: 7860-65.

World Bank. 1992. World development report: Development and the environment. Oxford: Oxford University Press.

- 2002. Improving air quality in metropolitan Mexico City. Policy Research Working Paper 2785. Washington, DC: World Bank.

World Resources Institute. 1994. World resources 1994-1995: A guide to the global environment. New York: Oxford University Press.

-1996. World resources 1996-1997: A guide to the global environment. New York: Oxford University Press.

Yandle, B., M. Bhattarai, and M. Vijayaraghavan. 2004. Environmental Kuznets curves: A review of findings, methods and policy implications.

Research study, 02-1, Bozeman, MT: Property and Environmental Research Center.

York, R., E. A. Rosa, and T. Dietz. 2003. STIRPAT, IPAT and ImPACT: Analytical tools for unpacking the driving forces of environmental impacts. Ecological Economics 46: 351-65. 